\section{Guidelines for cytogenetic case reports}

Many cytogenetic case reports are now being received and these vary greatly. The following guidelines may help authors to submit reports in a form which will be of greatest value to other workers.

The points the Editors will look for are as follows:

(1) An indication of the number of previous similar cases. We will consider for publication the first five or so reports of any one anomaly (defined as comparable events involving one particular chromosome arm) as simple case reports. If there are already more than about six such reports, there should be a definite attempt to describe a genotype/ phenotype correlation, with a tabulation giving a comparison between the current case and all previous cases.

(2) A clear, adequate, but not verbose, clinical description. Photographs of important features, such as a curious facial appearance, should be submitted.

(3) A clear statement of the karyotype of the patient giving details of the tissue used, method (including staining), and number of cells examined, especially where it is claimed that the patient is mosaic. Karyotypes without some form of banding would normally exclude the report from further consideration. In some cases $\mathrm{C}$ banding or NOR staining could be a requirement. Information on the karyotype of the patient's parents should always be included. A photograph of a full or partial karyotype should be submitted.

(4) Other useful laboratory investigations, such as red cell and serum enzymes, immunoglobulins, etc. These would enhance a report, but their absence would not necessarily rule out consideration of a case report. We would nevertheless expect this information from laboratories with access to the necessary technology.

(5) A short and relevant discussion.

(6) Length approximately 1000 words except where a serious review of previous cases is attempted when it could be a little longer.

(7) Only about eight references unless a review is presented.

(8) Poor English and bad spelling (where the report is from an author whose first language is not English) will not be a reason for exclusion unless it is so bad that the report is unintelligible.

(9) The Notice to Contributors on the inside front cover of the Journal should be followed on other matters.

D. G. HARNDEN 